BMJ Paediatrics Open

\title{
Anti-epileptic drug utilisation in paediatrics: a systematic review
}

\author{
Oluwaseun Egunsola, ${ }^{1}$ Imti Choonara, ${ }^{1}$ Helen M Sammons ${ }^{1,2}$
}

To cite: Egunsola 0, Choonara I, Sammons HM. Anti-epileptic drug utilisation in paediatrics: a systematic review. BMJ Paediatrics Open 2017;1:e000088. doi:10.1136/ bmjpo-2017-000088

- Additional material is published online only. To view please visit the journal online (http://dx.doi.org/10.1136/ bmjpo-2017-000088).

Received 21 May 2017 Revised 10 July 2017 Accepted 10 July 2017

\section{CrossMark}

${ }^{1}$ Division of Medical Sciences and Graduate Entry Medicine, University of Nottingham, Derbyshire Children's Hospital, Derby, UK

${ }^{2}$ Department of Paediatrics, North Devon District Hospital, Raleigh Park, Barnstaple, Devon, UK

Correspondence to Dr Oluwaseun Egunsola; seunegunsola@yahoo.com

\section{ABSTRACT}

Objectives This study aims to determine global antiepileptic drug (AED) utilisation prevalence and describe utilisation trends in different countries.

Methods Databases Embase (1980-May 2017), Medline (1946-May 2017) and PubMed were searched for original research on AED utilisation. All paediatric national or regional database studies and surveys were included. Results Twenty-one studies were identified. Five were excluded from the analysis as the data were collected before 2005, leaving 16 studies. Monotherapy regimen varied between $58 \%$ and $94 \%$ in different countries. In several of the studies, sodium valproate was the most frequently prescribed AED. However, there is a trend towards increasing utilisation of new-generation AEDs, particularly levetiracetam, in some countries.

Conclusion Monotherapy was used in 58\%-94\%of patients. There is increasing utilisation of the newgeneration AEDs, in particular lamotrigine, levetiracetam and topiramate. Old-generation AEDs are still used in the majority of patients. There is a need for up-to-date studies to determine the prevalence of AEDs in children.

\section{BACKGROUND}

In the last two decades, several new anti-epileptic drugs (AEDs) have been approved for the treatment of epilepsy. While the use of these new-generation drugs is growing, some of the old-generation drugs are still preferred because of cost and availability. Similar efficacy and safety have been reported for both generations of $\mathrm{AED}^{1}$; however, there are differences between specific drugs. ${ }^{2}$ Patient-specific factors such as age, gender, the type of epilepsy and the availability of monitoring also influence the choice of AEDs. The increasing utilisation of the new AEDs presents a fresh challenge of identifying new toxicities and drug interactions. For example, the increasing use of lamotrigine in Sweden resulted in an increase in the reports of adverse reactions to the drug. ${ }^{3}$

Drug utilisation studies provide an insight into the current standards and trends of drug prescriptions. Information from these studies can be used to evaluate and modify clinical prescribing policies and identify areas of research need. Electronic databases, such as

\section{What is already known on this topic?}

Sodium valproate is the most frequently prescribed anti-epileptic in paediatrics.

- There is an increasing prevalence of new-generation anti-epileptic drugs (AEDs).

\section{What this study hopes to add?}

Old-generation AEDs are still used for the majority of patients.

- Monotherapy was used in the majority of patients in all the studies.

administrative health databases, dispensing databases and health insurance records, provide a valuable tool for carrying out utilisation studies. In addition to identifying prescription trends, some databases can also provide background patient health information and can be used to evaluate treatment outcomes. ${ }^{4}$ Studies based on health insurance records may however underestimate actual drug use because drugs not reimbursed by national health services may not be recorded. ${ }^{56}$

In this systematic review, AED prescriptions in different countries were identified from the published literature.

\section{METHODS}

\section{Search strategy}

Databases Embase (1980-May 2017), Medline (1946-May 2017) and PubMed were searched for original research on AED utilisation (figure 1). Search terms used were "utilisation or utilization or pattern* or prescription or database or prescrib* or trend* or pharmacoepidemiol* or access or prevalence or practice or population or usage' in the title, combined with paediatric filters 'paediatric* or pediatric* or child*' in the title and 'anti-epileptic* or anti-epileptic* or anticonvulsant' also in the title. Google Scholar and 


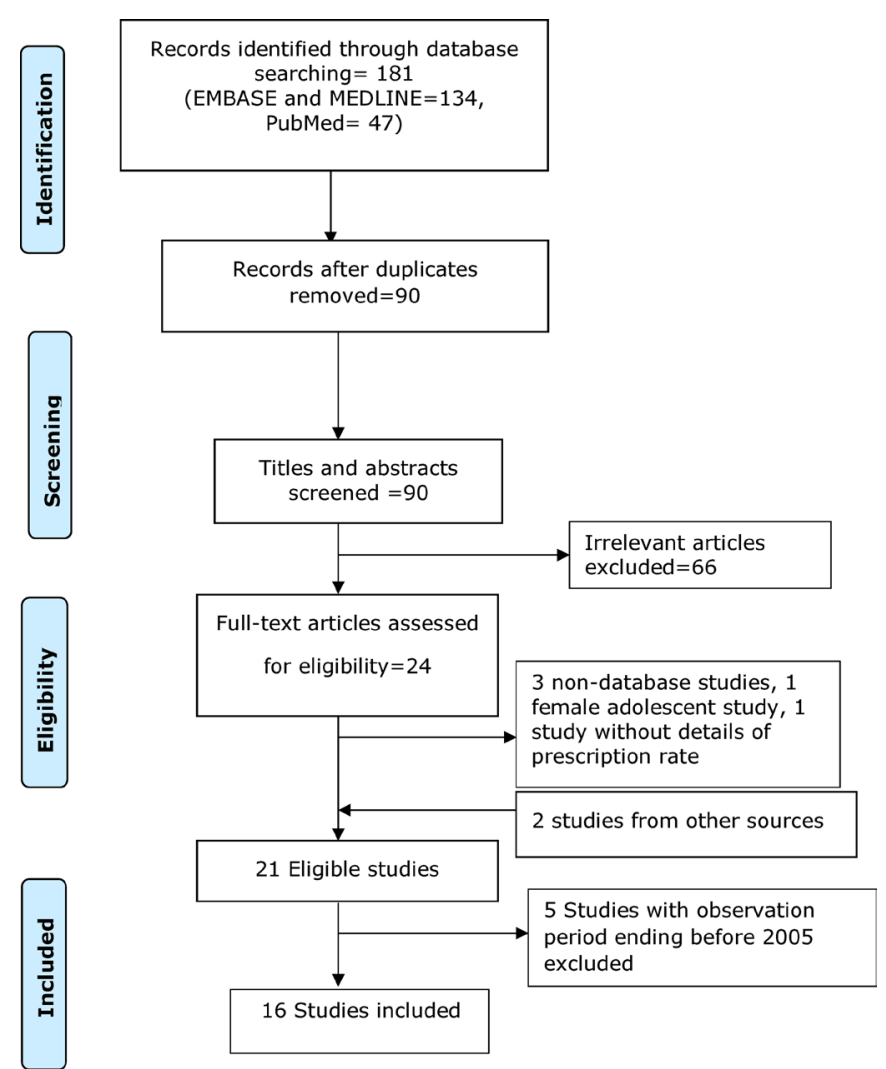

Figure 1 Flow chart of search outcome.

manual reference searches were also carried out. Only one reviewer carried out the search.

\section{Inclusion and exclusion criteria}

All paediatric national or regional database studies and surveys were included irrespective of language of publication. Single-centre studies were excluded. Mixed population studies in which the paediatric data were presented were also included. 'Paediatrics' was defined as any patient $\leq 18$ years old or as defined by the respective authors. Studies in which the percentage of AED utilisation was not presented or could not be calculated were excluded. Two reviewers determined eligibility for inclusion.

\section{Data extraction}

Data extracted from each study included year of study, country of study, setting, age of patients, study design, number of study participants, the type of AED and percentage of children receiving AED. Only one reviewer carried out the data extraction.

\section{RESULTS}

Twenty-one studies were identified. Five were excluded from the review as the data were collected before 2005 (online supplementary table 1). These were excluded because they were unlikely to adequately capture new AEDs. Monotherapy was the most common regimen, varying between $58 \%$ and $94 \%$ in different countries. Tables 1 and 2 describe the prescription rates of AEDs in Europe and other parts of the world, respectively. In several of the studies, sodium valproate was the most frequently prescribed AED, accounting for $7 \%-66 \%$ of prescriptions. A 9-year Dutch database review of AED prescriptions reported a sodium valproate prescription rate of $66 \%{ }^{7}$ (table 1). The lowest sodium valproate prescription rates were $12 \%$ and $7 \%$, reported in 2003 and 2007 in a Taiwanese population-based national health insurance study ${ }^{8}$ (table 2). Several studies showed a declining rate of sodium valproate utilisation. In the UK, the Clinical Practice Research Datalink (CPRD) database study reported a $56 \%$ prescription rate for sodium valproate in 1993, with subsequent decrease to $50 \%$ in 2008. ${ }^{9}$ Between 2005 and 2009, sodium valproate prescription rate declined from $58 \%$ to $36 \%$ in Hong Kong, ${ }^{10}$ while a marginal decline from $40 \%$ to $38 \%$ between 2000 and 2009 was recorded in a study at the only children's hospital in Singapore ${ }^{11}$ (figure 2).

Carbamazepine was the second most frequently prescribed AED in several countries (tables 1 and 2). Similar to sodium valproate, carbamazepine prescription rates have also shown a declining trend. The Welsh Secure Anonymised Information Linkage (SAIL) database recorded a prescription rate of $14 \%$ in 2001 compared with $10 \%$ a decade later ${ }^{12}$ (figure 2 ). Similarly, a $2 \%$ decline to $30 \%$ was reported in Hong Kong between 2005 and 2009. ${ }^{10}$ In Taiwan, a minimal decline from $7 \%$ in 2003 to 6\% in 2007 was reported. ${ }^{8}$ However in Singapore, a $4 \%$ increase in carbamazepine prescribing over a decade (2000-2009) was reported ${ }^{11}$ (figure 2).

Phenobarbital utilisation was highly variable in different countries, with prescription rates varying between $1 \%$ and $65 \%$. Phenobarbital prescribing has been higher in Asia, accounting for $8 \%, 13 \%$ and $24 \%$ of all AEDs used in Hong Kong (2009), ${ }^{10}$ Singapore (2009) ${ }^{11}$ and Taiwan (2007), ${ }^{8}$ respectively (table 1 ), compared with $2 \%$ and $5 \%$ in the UK (2008) ${ }^{9}$ and the Netherlands $(2006),{ }^{7}$ respectively (table 2). Phenytoin prescriptions ranged between $1 \%$ and $4 \%$ in all studies, with only marginal changes in prescription rates observed in the last two decades (tables 1 and 2).

Lamotrigine was the most frequently prescribed new-generation AED in several countries, with prescription rates ranging from $1 \%$ to $34 \%$. The highest prescription rate of $34 \%$ was recorded in a 2000-2007 Norwegian Prescription Database study. ${ }^{13}$ The UK CPRD (1993-2008) study and the Welsh SAIL database study (2000-2010) showed rising prescription prevalence, with prescribing increasing from $4 \%$ and $11 \%$ in 2000 to $22 \%$ and $21 \%$ in 2010 , respectively. However, studies in Hong Kong and Singapore reported a marginal decline in lamotrigine prescription rate. In Taiwan, a 9\% decline in prescription rate was reported between 2003 and 2007 (figure 3).

Levetiracetam prescription rate increased by $10 \%$ within 8 years after 2000 in the $\mathrm{UK}^{9}$ and $8 \%$ within 10 years in Wales. ${ }^{12}$ In Taiwan, the prescription rate of 


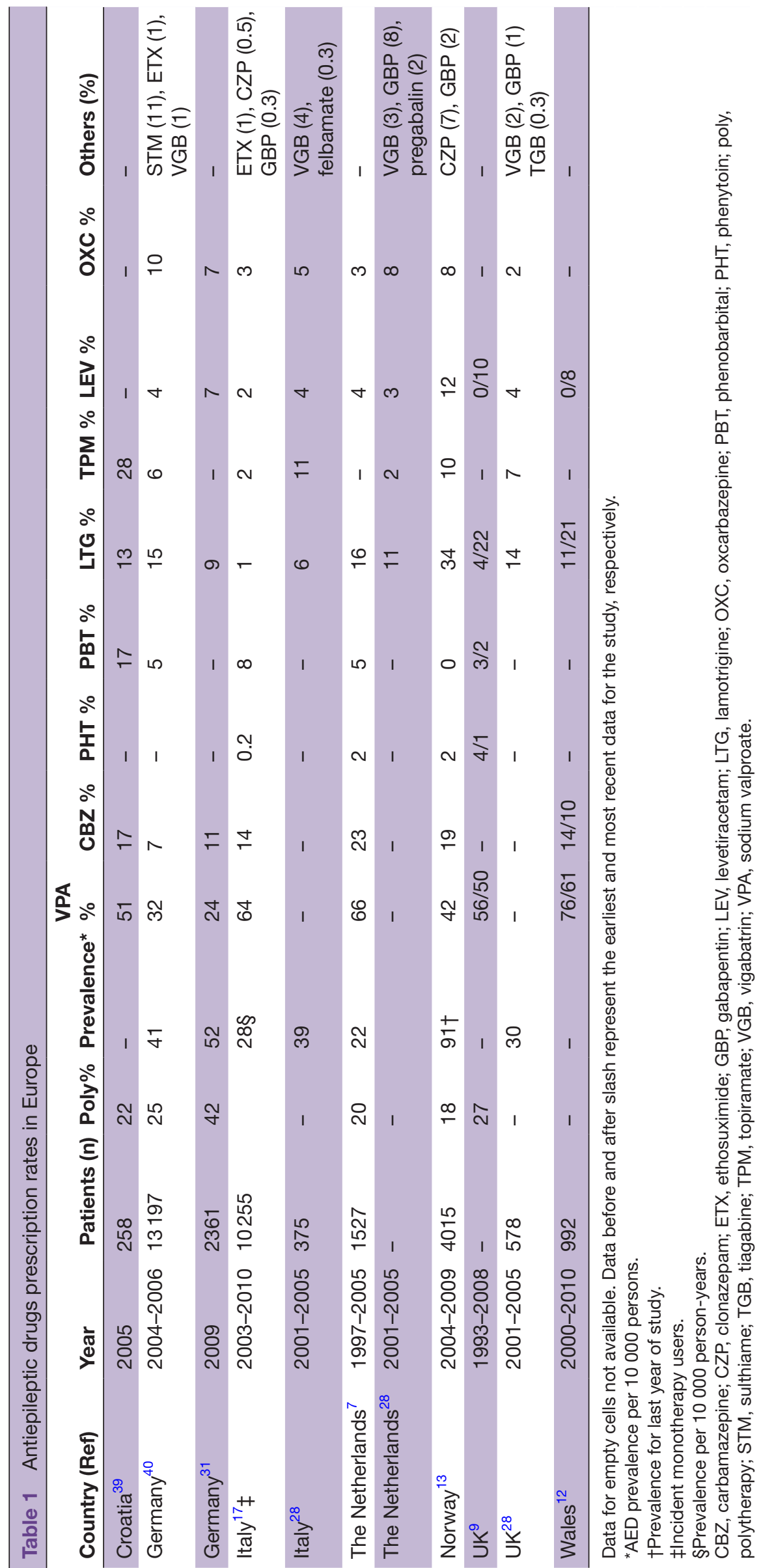




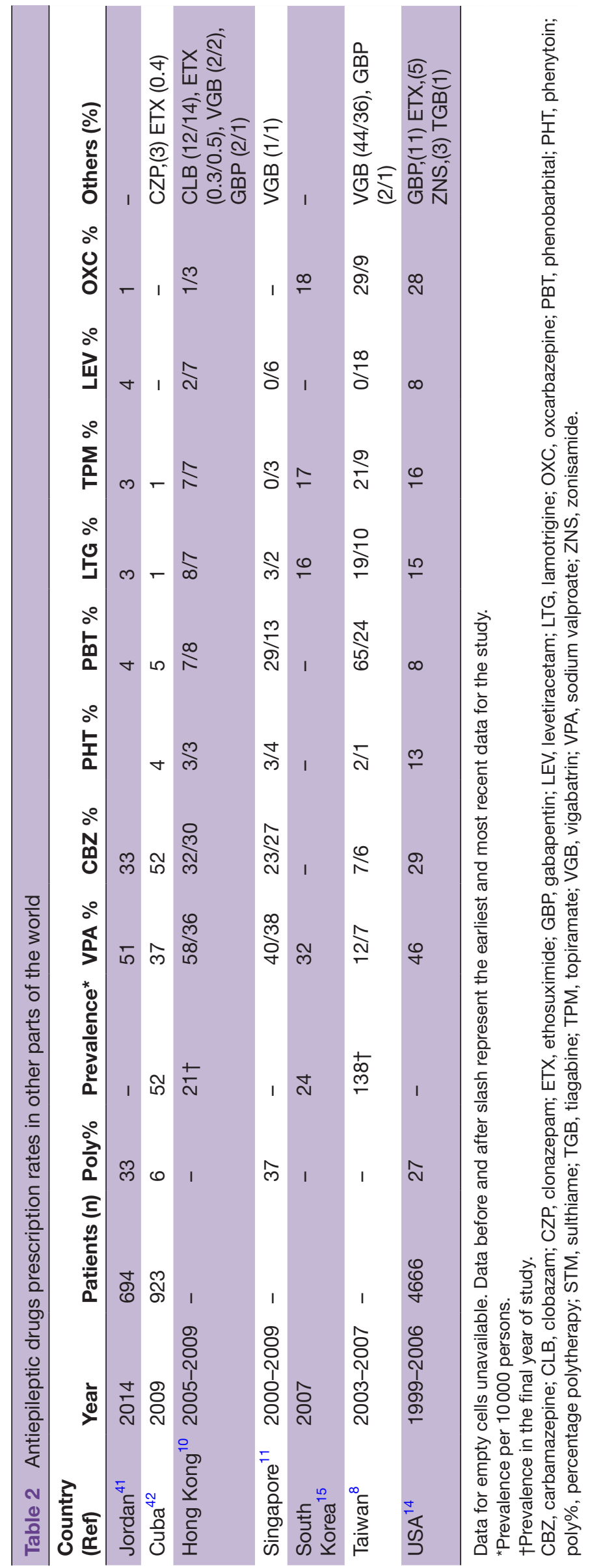

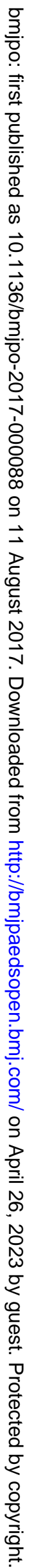




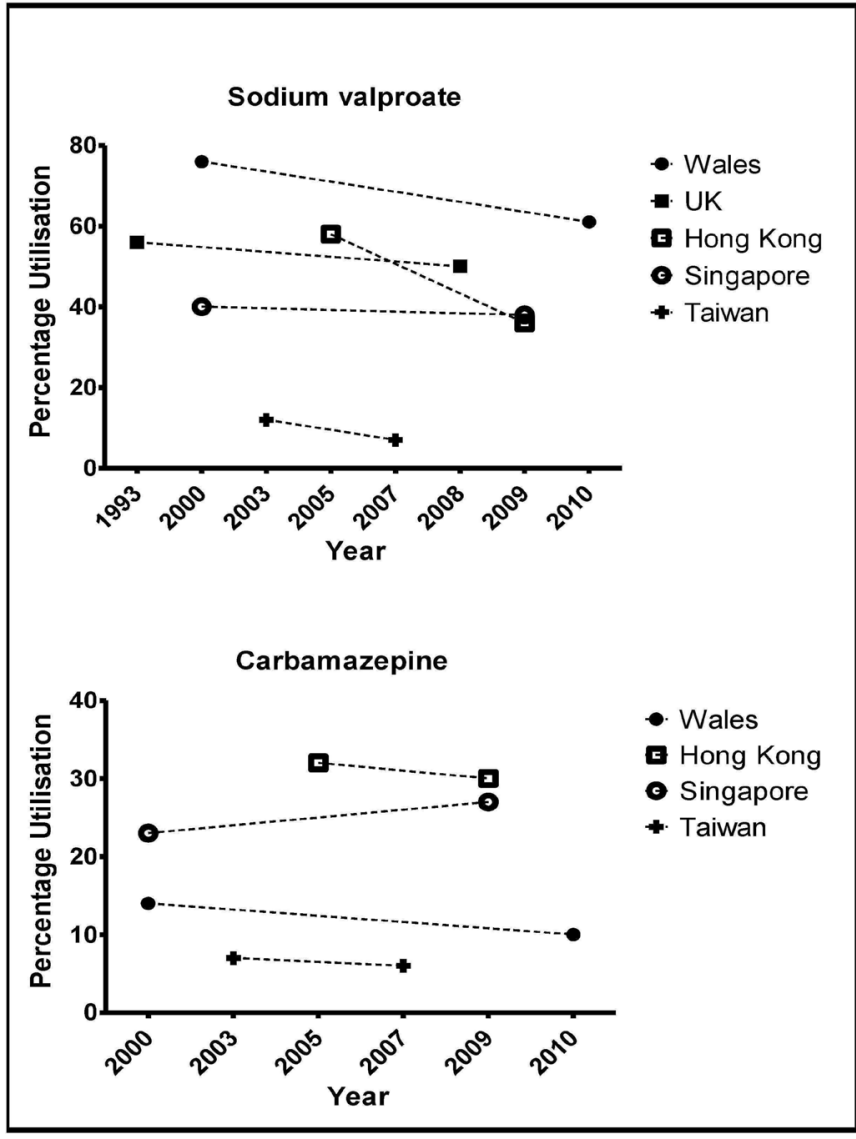

Figure 2 Sodium valproate and carbamazepine utilisation trends.

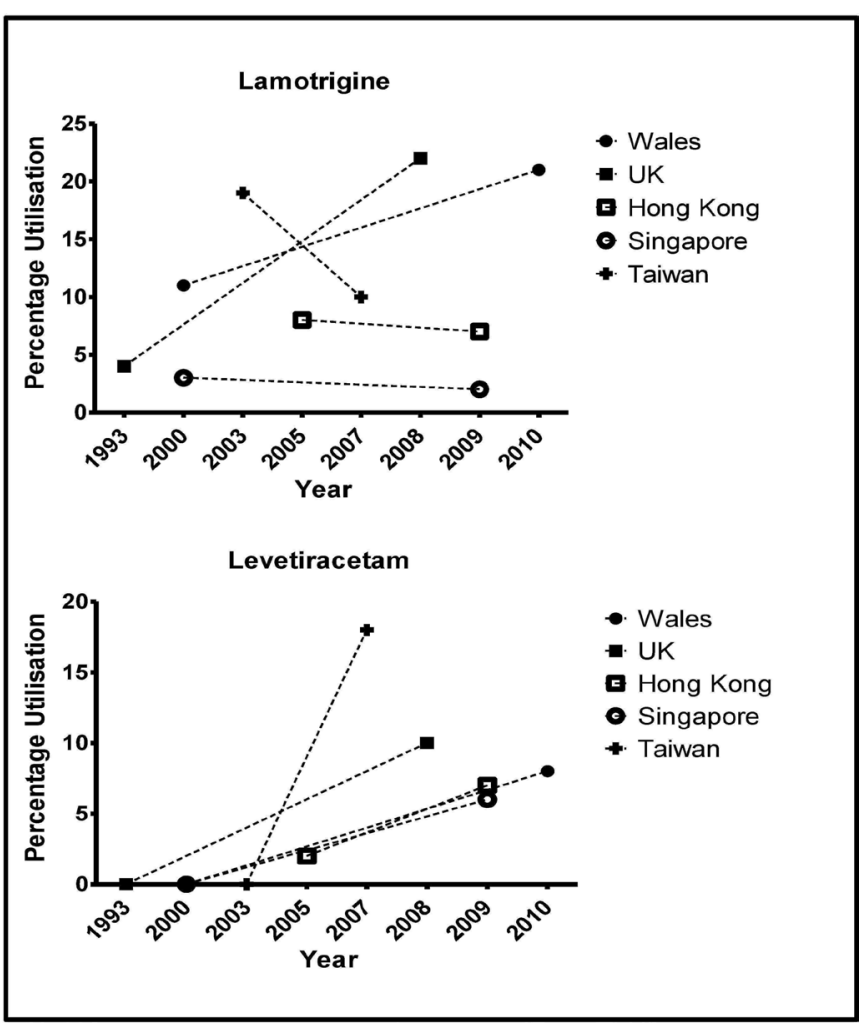

Figure 3 Lamotrigine and levetiracetam utilisation trends. levetiracetam rose from $0 \%$ in 2003 to $18 \%$ in $2007^{8}$ (figure 3), while topiramate prescription rate in Taiwan decreased from $21 \%$ in 2003 to $9 \%$ fouryears after. Between 1999 and 2006, oxcarbazepine was 28\% in the USA. ${ }^{14}$ In 2007, data from the South Korean health insurance database reported oxcarbazepine as the second most frequently prescribed AED, accounting for $18 \%$ of all AEDs prescribed. ${ }^{15}$

In most countries, vigabatrin utilisation varied between $1 \%$ and $4 \%$. However, prescription was high in Taiwan between 2003 (44\%) and 2007 (36\%). In 2007, it was the most frequently prescribed AED in Taiwan and the second most prescribed in 2003. In Hong Kong, vigabatrin prescription rate was 2\% in 2005 and 2009, respectively (table 2 ).

\section{DISCUSSION}

Sodium valproate was the most frequently prescribed AED in children in most countries. The broad spectrum of activity of the drug may be responsible for its continued preference for the management of paediatric epilepsy. Although current guidelines recommend both sodium valproate and carbamazepine as first-line antiepileptic agents ${ }^{16}$ lamotrigine, oxcarbazepine and levetiracetam utilisation is growing. ${ }^{14}$ This study showed a declining prevalence of all old-generation AEDs and a mixed trend in the utilisation rates of lamotrigine and topiramate. There was a general increase in the use of levetiracetam. Putignano et $a l^{17}$ attributed the increase in new AED utilisation in a region in Italy to increased levetiracetam use.

There was generally a mixed trend with carbamazepine utilisation in countries with high Han ethnic population, Singapore, Hong Kong and Taiwan. Carbamazepine utilisation was high in Hong Kong and Singapore, but low in Taiwan. The utilisation of oxcarbazepine, which is structurally similar to carbamazepine, declined from $29 \%$ to $9 \%$ between 2003 and 2007 in Taiwan. It is unclear how recommendations for genetic testing ${ }^{18}{ }^{19}$ in this population have impacted on carbamazepine and oxcarbazepine use. Recent data from a teaching hospital in the Shanghai region of China showed a $30 \%$ and $1 \%$ for oxcarbazepine and carbamazepine, respectively. ${ }^{20}$ The high rate of use of oxcarbazepine in China is surprising in view of the known predisposition of this population to the development of Stevens-Johnson syndrome. ${ }^{21} 22$

The rising prevalence of new-generation AEDs may be attributed to their increased utilisation for other indications, such as psychiatric disorders (lamotrigine) ${ }^{23}$ and pain (gabapentin and oxcarbazepine). ${ }^{24}{ }^{25}$ One adult study reported a 55-fold increase in non-seizure gabapentin prescription over 15 years in Canada. ${ }^{26} \mathrm{~A}$ recent safety alert by the UK Medicines and Healthcare products Regulatory Agency (MHRA) is likely to further reduce the utilisation of valproate in the UK. The report showed that up to $40 \%$ of children exposed in utero to the drug are at a high risk of serious developmental disorders and up to $10 \%$ at risk of congenital malformations. ${ }^{27}$ 
Consequently, the MHRA recommended the avoidance of valproate prescription to female children, female adolescents, women of childbearing potential or pregnant women unless other treatments are ineffective or not tolerated. ${ }^{27}$

The prescribing patterns of AEDs in children vary among countries because of differences in healthcare systems, cost of medicines, availability of drugs, as well as local and national epilepsy management guidelines. ${ }^{28}$ New-generation AEDs are generally more expensive; hence, prescriptions are less prevalent in low-income countries and countries with poor health insurance coverage. For instance, phenobarbital accounted for about two-thirds of AED prescriptions in a large Ethiopian adult study (2010-2012), while $30 \%$ of prescriptions were for phenytoin. ${ }^{29} \mathrm{~A}$ similar trend was reported in an Indian study in which over $95 \%$ of prescriptions were old-generation drugs. ${ }^{30}$ In high-income countries, the cost of some new-generation AEDs is sometimes not covered by the national health insurance or subsidy programmes. In Singapore, for instance, a 2012 study by Tan et $a l^{11}$ reported that only sodium valproate, carbamazepine, phenobarbital and phenytoin were subsidised by the government. Similarly, Hamer $e t a l^{31}$ also reported that reimbursement rules in Germany favour the preferential use of low-priced generic AEDs. The Pharmaceutical Benefit Scheme in Australia also limits the use of several new-generation AEDs. ${ }^{32}$

There are several limitations to this study. The studies included in this review are very heterogeneous and there are differences in the periods covered by each study. The data sources are diverse and the years of publication different. These limitations make direct comparison of AED utilisation between studies and countries difficult. The difficulties with comparative evaluation of drug utilisation studies have also been identified in a previous study. ${ }^{33}$ Many of the studies in this review are old and may not be reflective of the current utilisation rates in the respective countries. AED utilisation is dynamic and only new studies can adequately describe the current prescribing pattern in the respective countries. Although there are several published single-centre AED utilisation studies, ${ }^{34-36}$ these have not been included in this review because they may not be generalisable. Some studies with AED prescription prevalence reported as person-years were also excluded. ${ }^{37} 38$ Most of the studies reported on polytherapy use at the time of data review rather than at a defined point during treatment. This is likely to account for the variability in polytherapy utilisation observed in this study. Only one study reported incident polytherapy users. ${ }^{17}$

In conclusion, therapeutic options for the management of childhood epilepsy have increased with the introduction and increasing utilisation of new-generation AEDs. Lamotrigine, levetiracetam and oxcarbazepine are some of the most commonly prescribed new-generation drugs. There is a need for up-to-date database studies to determine the prevalence of AEDs in children.
Competing interests None declared.

Provenance and peer review Not commissioned; externally peer reviewed.

Open Access This is an Open Access article distributed in accordance with the Creative Commons Attribution Non Commercial (CC BY-NC 4.0) license, which permits others to distribute, remix, adapt, build upon this work non-commercially, and license their derivative works on different terms, provided the original work is properly cited and the use is non-commercial. See: http://creativecommons.org/ licenses/by-nc/4.0/

(C) Article author(s) (or their employer(s) unless otherwise stated in the text of the article) 2017. All rights reserved. No commercial use is permitted unless otherwise expressly granted.

\section{REFERENCES}

1. Weijenberg A, Offringa M, Brouwer OF, et al. RCTs with new antiepileptic drugs in children: a systematic review of monotherapy studies and their methodology. Epilepsy Res 2010;91:1-9.

2. Marson AG, Al-Kharusi AM, Alwaidh M, et al. The SANAD study of effectiveness of carbamazepine, gabapentin, Lamotrigine, oxcarbazepine, or topiramate for treatment of partial epilepsy: an unblinded randomised controlled trial. Lancet 2007;369:1000-15.

3. Kimland E, Rane A, Ufer M, et al. Paediatric adverse drug reactions reported in Sweden from 1987 to 2001. Pharmacoepidemiol Drug Saf 2005;14:493-9.

4. Loke YK. Use of databases for clinical research. Arch Dis Child 2014;99:587-9.

5. Clavenna A, Bonati M. Differences in antibiotic prescribing in paediatric outpatients. Arch Dis Child 2011:96:590-5.

6. Clavenna A, Bonati M. Drug prescriptions to outpatient children: a review of the literature. Eur J Clin Pharmacol 2009;65:749-55.

7. van de Vrie-Hoekstra NW, de Vries TW, van den Berg PB, et al. Antiepileptic drug utilization in children from 1997-2005--a study from the Netherlands. Eur J Clin Pharmacol 2008;64:1013-20.

8. Hsieh LP, Huang CY. Trends in the use of antiepileptic drugs in Taiwan from 2003 to 2007: a population-based national health insurance study. Epilepsy Res 2011;96:81-8.

9. Nicholas JM, Ridsdale L, Richardson MP, et al. Trends in antiepileptic drug utilisation in UK primary care 1993-2008: cohort study using the General Practice Research Database. Seizure 2012;21:466-70.

10. Kwong KL, Tsui KW, Wu SP, et al. Utilization of antiepileptic drugs in Hong Kong children. Pediatr Neurol 2012;46:281-6.

11. Tan WW, Kong ST, Chan DW, et al. A retrospective study on the usage of antiepileptic drugs in asian children from 2000 to 2009 in the largest pediatric hospital in Singapore. Pharmacoepidemiol Drug Saf 2012;21:1074-80.

12. Pickrell WO, Lacey AS, Thomas RH, et al. Trends in the first antiepileptic drug prescribed for epilepsy between 2000 and 2010. Seizure 2014;23:77-80.

13. Landmark CJ, Fossmark H, Larsson PG, et al. Prescription patterns of antiepileptic drugs in patients with epilepsy in a nation-wide population. Epilepsy Res 2011;95:51-9.

14. Bourgeois FT, Olson KL, Poduri A, et al. Comparison of drug utilization patterns in Observational Data: antiepileptic drugs in Pediatric Patients. Paediatr Drugs 2015;17:401-10.

15. Lee SY, Jung KY, Lee IK, et al. Prevalence of treated epilepsy in Korea based on national health insurance data. $J$ Korean Med Sci 2012;27:285-90.

16. National Institute for Health and Clinical Excellence. The epilepsies: the diagnosis and management of the epilepsies in adults and children in primary and secondary care, 2012. Available from. guidance.nice.org.uk/cg137.

17. Putignano D, Clavenna A, Campi R, et al. Antiepileptic drug use in italian children over a decade. Eur J Clin Pharmacol 2017;73:241-8.

18. Amstutz $U$, Shear $\mathrm{NH}$, Rieder MJ, et al. Recommendations for HLA-B*15:02 and HLA-A*31:01 genetic testing to reduce the risk of carbamazepine-induced hypersensitivity reactions. Epilepsia 2014;55:496-506.

19. Leckband SG, Kelsoe JR, Dunnenberger HM, et al. Clinical pharmacogenetics implementation Consortium guidelines for HLA-B genotype and carbamazepine dosing. Clin Pharmacol Ther 2013;94:324-8.

20. Yan W ZL. Utilization of antiepileptic drugs on Monotherapy and Polytherapy for Children at Shanghai in China. Int JPharmacol 2016;12:496-504.

21. Chen CB, Hsiao $\mathrm{YH}, \mathrm{Wu} \mathrm{T}$, et al. Risk and association of HLA with oxcarbazepine-induced cutaneous adverse reactions in Asians. Neurology 2017;88:78-86. 
22. Hung SI, Chung WH, Liu ZS, et al. Common risk allele in aromatic antiepileptic-drug induced Stevens-Johnson syndrome and toxic epidermal necrolysis in Han Chinese. Pharmacogenomics 2010;11:349-56.

23. Bowden CL, Asnis GM, Ginsberg LD, et al. Safety and tolerability of lamotrigine for bipolar disorder. Drug Saf 2004;27:173-84.

24. Serpell MG, Group NPS; Neuropathic pain study group. Gabapentin in neuropathic pain syndromes: a randomised, double-blind, placebo-controlled trial. Pain 2002;99:557-66.

25. Zhou M, Chen N, He L, et al. Oxcarbazepine for neuropathic pain: The Cochrane Library, 2013.

26. Leong C, Mamdani MM, Gomes T, et al. Antiepileptic use for epilepsy and nonepilepsy disorders: a population-based study (1998-2013). Neurology 2016;86:939-46.

27. Medicines and Healthcare products Regulatory Agency. Valproate and risk of abnormal pregnancy outcomes: new communication materials, 2016. https://www.gov.uk/drug-safety-update/valproateand-of-risk-of-abnormal-pregnancy-outcomes-new-communicationmaterials

28. Hsia Y, Neubert A, Sturkenboom MC, et al. Comparison of antiepileptic drug prescribing in children in three european countries. Epilepsia 2010;51:789-96.

29. Gurshaw M, Agalu A, Chanie T. Anti-epileptic drug utilization and treatment outcome among epileptic patients on followup in a resource poor setting. Journal of Young Pharmacists 2014;6:47-52.

30. Pal A, Prusty SK, Sahu PK, et al. Drug utilization pattern of antiepileptic drugs: a pharmacoepidemiologic and pharmacovigilance study in a tertiary teaching hospital in India. Asian J Pharm Clin Res 2011;4:96-9.

31. Hamer HM, Dodel R, Strzelczyk A, et al. Prevalence, utilization, and costs of antiepileptic drugs for epilepsy in Germany--a nationwide population-based study in children and adults. J Neurol 2012;259:2376-84.
32. The Australian Government Department of Health. Pharmaceutical Benefits Scheme. http://www.pbs.gov.au.

33. Rossignoli A, Clavenna A, Bonati M. Antibiotic prescription and prevalence rate in the outpatient paediatric population: analysis of surveys published during 2000-2005. Eur J Clin Pharmacol 2007;63:1099-106.

34. Anderson M, Egunsola O, Cherrill J, et al. A prospective study of adverse drug reactions to antiepileptic drugs in children. BMJ Open 2015;5:e008298.

35. Malerba A, Ciampa C, De Fazio S, et al. Patterns of prescription of antiepileptic drugs in patients with refractory epilepsy at tertiary referral centres in Italy. Epilepsy Res 2010;91:273-82.

36. Hasan SS, Bahari MB, Babar ZU, et al. Antiepileptic drug utilisation and seizure outcome among paediatric patients in a malaysian public hospital. Singapore Med J 2010;51:21.

37. Ackers R, Besag FM, Wade A, et al. Changing trends in antiepileptic drug prescribing in girls of child-bearing potential. Arch Dis Child 2009;94:443-7.

38. Cohen SA, Lawson JA, Graudins LV, et al. Changes in anticonvulsant prescribing for australian children: implications for Quality Use of Medicines. J Paediatr Child Health 2012:48:490-5. Image Legend.

39. Bielen I, Sruk A, Planjar-Prvan M, et al. Age-related pattern of the antiepileptic drug utilization in active epilepsy: a population-based survey. Coll Antropol 2009;33:659-63.

40. Dörks M, Langner I, Timmer A, et al. Treatment of paediatric epilepsy in Germany: antiepileptic drug utilisation in children and adolescents with a focus on new antiepileptic drugs. Epilepsy Res 2013;103:45-53.

41. Albsoul-Younes A, Gharaibeh L, Murtaja AA, et al. Patterns of antiepileptic drugs use in epileptic pediatric patients in Jordan. Neurosciences 2016;21:264-7.

42. Arencibia ZB, Leyva AL, Peña YM, et al. Access to antiepileptic drug therapy in children in Camagüey Province, Cuba. Int $J$ Pharm Pract 2012;20:390-4. 